\title{
The Turbulent Lagrangian Time Scale in Forest Canopies Constrained by Fluxes, Concentrations and Source Distributions
}

\author{
Vanessa Haverd · Ray Leuning • David Griffith • \\ Eva van Gorsel · Matthias Cuntz
}

Received: 26 March 2008 / Accepted: 8 December 2008 / Published online: 7 January 2009

(C) The Author(s) 2009. This article is published with open access at Springerlink.com

\begin{abstract}
One-dimensional Lagrangian dispersion models, frequently used to relate in-canopy source/sink distributions of energy, water and trace gases to vertical concentration profiles, require estimates of the standard deviation of the vertical wind speed, which can be measured, and the Lagrangian time scale, $T_{L}$, which cannot. In this work we use nonlinear parameter estimation to determine the vertical profile of the Lagrangian time scale that simultaneously optimises agreement between modelled and measured vertical profiles of temperature, water vapour and carbon dioxide concentrations within a 40-m tall temperate Eucalyptus forest in south-eastern Australia. Modelled temperature and concentration profiles are generated using Lagrangian dispersion theory combined with source/sink distributions of sensible heat, water vapour and $\mathrm{CO}_{2}$. These distributions are derived from a multilayer Soil-Vegetation-Atmospheric-Transfer model subject to multiple constraints: (1) daytime eddy flux measurements of sensible heat, latent heat, and $\mathrm{CO}_{2}$ above the canopy, (2) in-canopy lidar measurements of leaf area density distribution, and (3) chamber measurements of $\mathrm{CO}_{2}$ ground fluxes. The resulting estimate of Lagrangian time scale within the canopy under near-neutral conditions is about 1.7 times higher than previous estimates and decreases towards zero at the ground. It represents an advance over previous estimates of $T_{L}$, which are largely unconstrained by measurements.
\end{abstract}

Keywords Atmospheric dispersion - Lagrangian time scale - Micrometeorology · Turbulent transport · Plant canopies

V. Haverd $(\varangle) \cdot$ R. Leuning $\cdot$ E. van Gorsel

CSIRO Marine and Atmospheric Research, GPO Box 3023, Canberra, ACT 2601, Australia

e-mail: Vanessa.Haverd@csiro.au

V. Haverd · D. Griffith

Department of Chemistry, University of Wollongong, Wollongong, NSW 2522, Australia

M. Cuntz

Research School of Biological Sciences, GPO Box 475, Canberra, ACT 2601, Australia

Present Address:

M. Cuntz

Max-Planck-Institut für Biogeochemie, Hans-Knöll-Str. 10, 07745 Jena, Germany 


\section{Introduction}

Vertical source/sink distributions of scalars in plant canopies have been estimated previously (Denmead 1991; Katul et al. 1997; Leuning 2000; Leuning et al. 2000; Siqueira et al. 2002, 2003; Denmead et al. 2005; Tiwary et al. 2007) using measured vertical scalar concentration profiles combined with a prescribed turbulence dispersion field. Each of these studies used an assumed or calculated turbulent dispersion field to link the scalar source/sink distributions and the concentration profiles. Large errors in the inferred sources/sinks can arise from uncertainties in knowledge of the dispersion field (Leuning et al. 2000; Siqueira et al. 2002). This study aims to reduce this source of uncertainty in one class of dispersion model, the one-dimensional, Localised Near-Field (LNF) theory of Raupach (1989a,b). The LNF requires knowledge of the vertical variation of $\sigma_{w}$, the standard deviation of vertical velocity fluctuations, and $T_{L}$, the Lagrangian time scale, which quantifies the persistence of the turbulence. While it is possible to measure directly the vertical profile of $\sigma_{w}$, this is not the case for $T_{L}$ and considerable uncertainty exists in the variation of $T_{L}$ within the canopy. Here we assess the performance of two functional forms of $T_{L}$ that have been proposed in the literature (Massman and Weil 1999; Styles et al. 2002). We solve for the initially unknown profile of $T_{L}$ by using measured profiles of $\sigma_{w}$, temperature and mixing ratios of water vapour and $\mathrm{CO}_{2}$ within a forest, in conjunction with their corresponding source/sink distributions calculated using an advanced multilayer Soil-Vegetation-Atmospheric-Transfer (SVAT) model (Leuning et al. 1995). We show that the measured scalar profiles and modelled source/sink distributions are sufficiently accurate to discriminate between alternative forms of the proposed $T_{L}$ profile. Confidence in model predictions is high because they were constrained by net fluxes measured above the canopy, by chamber measurements of $\mathrm{CO}_{2}$ fluxes and by Lidar measurements of the vertical leaf area density distribution.

Section 2 describes the theory of dispersion within canopies and provides details of our approach to estimating $T_{L}$. In Sect. 3 we present the source distributions, turbulence statistics and measured concentration profiles required to infer $T_{L}$. In Sect.4, we compare predicted and observed concentration profiles, and present optimized profiles of $T_{L}$.

\section{Theory and Approach to Determining Profiles of $T_{L}$}

The relationship between the vertical distribution of scalar source/sinks and scalar concentrations within plant canopies may be written in finite-difference form as:

$$
c_{i}-c_{r e f}=\sum_{j=1}^{m} D_{i j} S_{j} \Delta z_{j}
$$

in which $c_{i}$ and $c_{r e f}$ are, respectively, the concentration at height above the ground $\mathrm{z}_{i}$, and at a reference height ( $z_{\text {ref }}$, typically above the canopy), $S_{j}$ is the source/sink at height $j$ distributed across a layer of thickness $\Delta z_{j}$, and $D_{i j}$ are the elements of the dispersion matrix relating $c_{i}$ to $S_{j}$.

Calculation of the dispersion matrix $D_{i j}$ requires knowledge of $\sigma_{w}$, the vertical profile of the standard deviation of vertical velocity fluctuations, and $T_{L}$, the Lagrangian time scale. In the widely used Localised Near-Field (LNF) theory of Raupach (1989a,b), the concentration in Eq. 1 is expressed as the sum of near-field and far-field components $\left(c_{i}=c_{n i}+c_{f i}\right)$. The diffusive far-field component, $c_{f}$, provides large-scale variations in the concentration profile, upon which is superimposed detailed local structure due to $c_{n}$, the non-diffusive 
near-field component. The continuous forms of the near- and far-field concentration components depend on $\sigma_{w}$ and $T_{L}$ as follows:

$$
\begin{gathered}
c_{n}(z)=\int_{0}^{\infty} \frac{S\left(z_{S}\right)}{\sigma_{w}\left(z_{S}\right)}\left\{k_{n}\left[\frac{z-z_{S}}{\sigma_{w}\left(z_{S}\right) \mathrm{T}_{L}\left(z_{S}\right)}\right]+k_{n}\left[\frac{z+z_{S}}{\sigma_{w}\left(z_{S}\right) \mathrm{T}_{L}\left(z_{S}\right)}\right]\right\} \mathrm{d} z_{S}, \\
c_{f}(z)=c_{f}\left(z_{\text {ref }}\right)+\int_{z}^{z_{\text {ref }}} \frac{F\left(z^{\prime}\right)}{K_{f}\left(z^{\prime}\right)} \mathrm{d} z^{\prime} .
\end{gathered}
$$

In Eqs. 2 and 3, $z_{s}$ is the source height $z_{\text {ref }}$ is an arbitrary reference height, $k_{n}$ is a 'nearfield kernel' approximated by: $k_{n}(\varsigma)=-0.3989 \ln (1-\exp (-|\varsigma|))-0.1562 \exp (-|\varsigma|)$, $c_{f}\left(z_{\text {ref }}\right)=c\left(z_{\text {ref }}\right)-c_{n}\left(z_{\text {ref }}\right), F(z)$ is the flux density, related to the source strength by $F(z)=\int_{0}^{z} S\left(z^{\prime}\right) \mathrm{d} z^{\prime}$ and to the far-field concentration by the gradient diffusion relationship $F(z)=-K_{f}(z) \mathrm{d} c_{f} / \mathrm{d} z$, where $K_{f}$ is the far-field diffusivity, $K_{f}=\sigma_{w}^{2}(z) T_{L}(z)$.

To calculate the elements $D_{i j}$ we follow Raupach (1989a). Consider a scalar that is released uniformly in layer $j$ with source strength, $S_{j}$, but with zero strength in all other layers. The resulting partial concentration profile $c_{i}$ defines the elements of the dispersion matrix for dispersion from layer $j$ to concentration at height $\mathrm{z}_{i}$, ie.

$$
D_{i j}=\frac{c_{i}-c_{R}}{S_{j} \Delta z_{j}}
$$

Each element of $D_{i j}$ has a near-field and a far-field component because $c_{i}=c_{n i}+c_{f i}$.

We assume a unit source strength in each layer and use Eqs. 2 and 3 to estimate $c_{n i}$ and $c_{f i}$ and hence the coefficients $D_{i j}$ from Eq. 4, provided we know $\sigma_{w}(z)$ and $T_{L}(z)$.

While $\sigma_{w}(z)$ is measurable using an array of sonic anemometers on a single fixed tower, the vertical profile of $T_{L}$ is not. $T_{L}$ is often estimated from single-point estimates of the Eulerian time scale $\left(T_{E}\right)$ :

$$
T_{L}=\beta \bar{u} T_{E} / \sigma_{w}
$$

with

$$
T_{E}=\int_{0}^{\infty} \frac{w^{\prime}(t) w^{\prime}(t+\tau)}{\sigma_{w}^{2}} \mathrm{~d} \tau,
$$

where $w^{\prime}=w-\bar{w}$ is the instantaneous deviation of the vertical wind velocity, $w$, from its time-averaged value, $\bar{w}, \bar{u}$ is the mean horizontal wind speed and $\beta$ is a constant of order 1 (Raupach 1989a). However use of Eq. 5 is problematic because of two assumptions used in its derivation: (1) the mean velocity approximates the convective velocity of eddies, which is only valid at low turbulence intensities, not typical within canopies, and (2) the Eulerian and Lagrangian velocity spectra are unperturbed by the presence of the canopy, and not influenced by short-circuiting of the energy cascade or wake production (Poggi et al. 2008). Alternatively, there are several parameterisations of $T_{L}$ in the literature, most of which are reviewed by Denmead et al. (2005). These generally agree on the form of $T_{L}$ under neutral stability in the inertial sublayer $\left(z / h_{c}>2\right)$ :

$$
\frac{T_{L} u_{*}}{h_{c}}=\frac{k(z-d)}{\left(\sigma_{w} / u_{*}\right)^{2} h_{c}},
$$




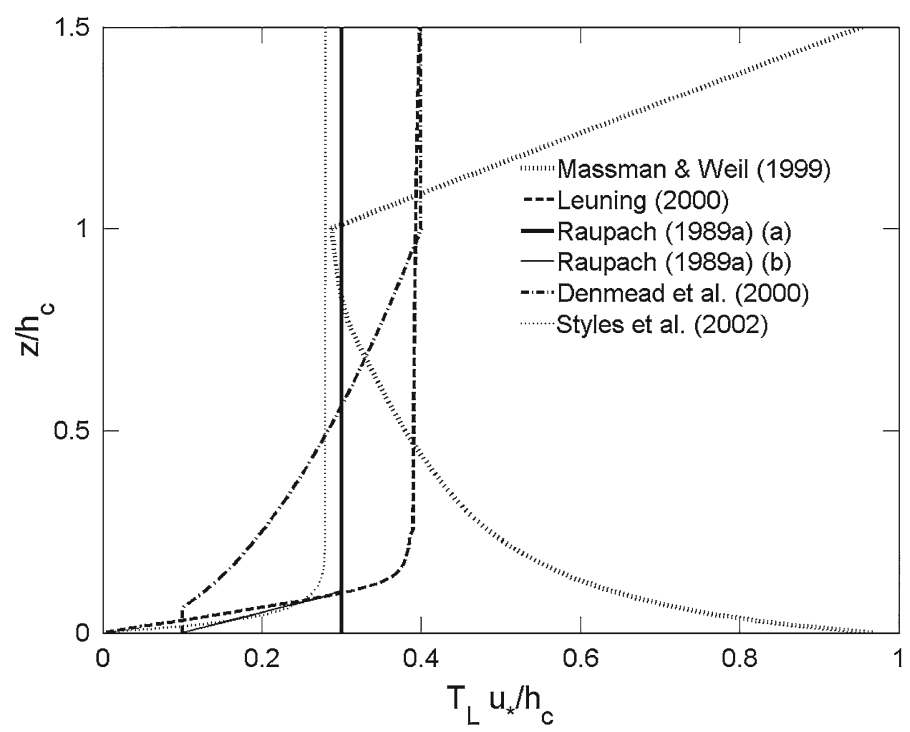

Fig. 1 Different parameterisations of the normalised Lagrangian time scale

which is obtained by matching the following expressions for the far-field diffusivity: $K_{f}=$ $k u_{*}(z-d)$ and $K_{f}=\sigma_{w}^{2} T_{L}$. Here $z$ is height above the ground, $h_{c}$ is canopy height, $k$ is the von Karman constant, $u_{*}$ is the friction velocity above the roughness sublayer, and $d$ is the zero-plane displacement. Equation 7 (with $d=0.8 h_{c}$ and $\sigma_{w} / u_{*}=1.25$ ) yields a value of $T_{L} u_{*} / h_{c}=0.32$ at the bottom of the inertial sublayer (top of the roughness sublayer), and $T_{L} u_{*} / h_{c}$ is assumed to remain constant at a value of 0.3-0.4 down to the top of the canopy $\left(z=h_{c}\right)$.

Several formulations have been proposed for $T_{L} u_{*} / h_{c}$ below $h_{c}$ and these are shown in Fig. 1. Raupach (1989a) suggested either a constant value of $T_{L} u_{*} / h_{c}=0.3$ throughout the canopy (based on far-field diffusivity measurements by Legg et al. (1986)) or a profile of $T_{L} u_{*} / h_{c}$ that remains constant at 0.3 from the top of the canopy until $z / h_{c}=0.1$ and then decreases to 0.1 at $z=0$. Katul et al. (1997) and Nemitz et al. (2000) also use a constant value of 0.3 within the canopy. In contrast, Raupach et al. (1992) and Denmead et al. (2000) allow $T_{L} u_{*} / h_{c}$ to decrease with canopy depth according to the power-law function, $T_{L} u_{*} / h_{c}=\max \left[0.4\left(z / h_{c}\right)^{1 / 2}, 0.1\right]$. Leuning (2000) and Leuning et al. (2000) used a constant value of 0.4 for the canopy down to $z / h_{c}=0.25$, consistent with the theory that turbulent transport in canopies is dominated by a single turbulence length scale (Raupach et al. 1996), and allowed $T_{L} u_{*} / h_{c}$ to decrease smoothly below this height to zero at the ground.

In a study to characterise soil and vegetation fluxes using in-canopy concentration measurements, Styles et al. (2002) proposed the following form of $T_{L} u_{*} / h_{c}$

$$
\frac{T_{L} u_{*}}{h_{c}}=c_{2} \frac{1-\exp \left(-c_{1} z / h_{c}\right)}{1-\exp \left(-c_{1}\right)},
$$

which can range from constant $\left(c_{1} \rightarrow \infty\right)$ to linear $\left(c_{1} \rightarrow 0\right)$, and can be used to approximate all the formulations introduced thus far. Values of $c_{1}$ and $c_{2}$ were optimized by Styles et al. (2002), such that the differences between measured and modelled concentration profiles of $\mathrm{CO}_{2}$, water vapour and air temperature were minimised. However the resulting values 
$\left(c_{1}=29\right.$ and $\left.c_{2}=0.32\right)$ were subject to large uncertainties owing to significant co-dependences of $c_{1}$ and $c_{2}$ with several other parameters and fluxes at the ground that were optimised simultaneously.

The above formulations contrast significantly with that of Massman and Weil (1999) (hereafter MW):

$$
\frac{T_{L}(z) u_{*}}{h_{c}}=A_{2}\left[\frac{\left(1-d / h_{c}\right)}{\sigma_{w}(z) / \sigma_{w}\left(h_{c}\right)}\right]^{1 / 2}
$$

in which $A_{2}$ is a constant. This relation predicts that $T_{L} u_{*} / h_{c}$ is proportional to $\sigma_{w}^{-1 / 2}(z)$ within the canopy, yielding increasing values of $T_{L} u_{*} / h_{c}$ with canopy depth, especially at high values of plant area density (see MW, Fig. 11).

We next describe an analysis that reduces uncertainty in the Lagrangian time scale. Equation 1 predicts concentration profiles from known source/sink distributions and specification of the dispersion matrix $D_{i j}$, and Denmead et al. (2000) and Leuning et al. (2000) inverted Eq. 1 to solve for unknown source/sink distributions using measured concentration and $\sigma_{w}$ profiles and assumed profiles of $T_{L}$ to calculate the required $D_{i j}$. However, Eq. 1 can also be used to solve for the elements of $D_{i j}$, and hence for the vertical profile of $T_{L}$, provided the profiles of $c_{i}-c_{r e f}, \sigma_{w}$ and $S_{j}$ are known. For his purpose, we use the above LNF theory of Raupach (1989b) using $\sigma_{w}$, interpolated from measurements in a forest, and an initial form for the $T_{L}$ profile (either Eq. 8 or 9 with prior values of the coefficients) to calculate a preliminary $D_{i j}$ matrix. Vertical source/sink profiles, $S_{j}$, of sensible heat, latent heat and $\mathrm{CO}_{2}$ were predicted using a multilayer SVAT model (Leuning et al. 1995), with key parameter values of the model optimized using fluxes measured above the canopy. The predicted $S_{j}$ distributions were combined with the prior estimates of $D_{i j}$ via Eq. 1 to predict temperature and scalar concentration profiles relative to the corresponding value at the canopy top. Nonlinear parameter estimation was then used to adjust the prior estimates of $T_{L}$ (and hence $D_{i j}$ ) to minimize a cost function of the residuals between predicted and observed concentration profiles. Note here that the SVAT model was forced using measured hourly meteorological data and measured hourly vertical profiles of $\mathrm{CO}_{2}$, water vapour and temperature. Thus the modelled source/sink profiles are independent of turbulence statistics $\left(\sigma_{w}\right.$ and $\left.T_{L}\right)$, allowing us to estimate the parameters determining $T_{L}$ separately from the SVAT model parameters.

\subsection{Measurements}

The measurement site is a $40 \mathrm{~m}$ tall temperate Eucalyptus forest at the Tumbarumba Ozflux site $\left(35.6557^{\circ} \mathrm{S}, 148.1521^{\circ} \mathrm{E}\right.$, elevation $\left.1,200 \mathrm{~m}\right)$ in south-east Australia. Here hourly vertical flux densities of $\mathrm{CO}_{2}\left(F_{c}\right)$, latent heat $(\lambda E)$ and sensible heat $(H)$ are measured continuously using the eddy-covariance technique, with sensors mounted on top of a $70 \mathrm{~m}$ mast (Leuning et al. 1995). Profiles of air temperature are measured using unventilated, $100 \mu \mathrm{m}$ copper-constantan thermocouples mounted beneath radiation shields on the mast. The mixing ratios of water vapour and $\mathrm{CO}_{2}$ are also measured routinely using a gas sampling system and an infrared gas analyser (LI6262, Licor Inc., Lincoln, Nebraska). High-precision water vapour and $\mathrm{CO}_{2}$ profiles were measured during a two-week campaign (November 13-26, 2006), using two portable Fourier transform infrared (FTIR) spectrometers. Air was sampled via heated Dekabon ${ }^{\mathrm{TM}}$ tubing $(9.525 \mathrm{~mm}$ diameter) from seven inlets $(2.0,4.4,10.4,26.3$, $35.4,43.4,70.1 \mathrm{~m}$ ) on the mast. Separate instruments were used for $\mathrm{CO}_{2}$ and water vapour so that the air could be dried prior to analysis for $\mathrm{CO}_{2}$, thus avoiding spectral interference from water vapour, which would have degraded $\mathrm{CO}_{2}$ measurement accuracy and precision. Flow 
in each of the seven lines was continuously purged at $21 \mathrm{~min}^{-1}$ and air was sampled in turn at the same flow rate for analysis using the FTIR spectrometers. The sampling time of $4.2 \mathrm{~min}$ included evacuation of the measurement cell down to $100 \mathrm{~Pa}$ to avoid contamination from previous sample, filling time, pre-measurement flow-through, measurement and recording of infrared spectra of the flowing sample and spectral analysis (Griffith 2002). In total, each point of the profile was sampled for 2 min out of the 30-min cycle required for the entire profile. The time series of concentration data at each level were interpolated linearly in time and re-sampled at the nearest integral hour to produce quasi-instantaneous vertical profiles. This procedure resulted in small adjustments compared to the observed vertical concentration variations.

For a short period (November 8-14, 2006) before and just overlapping the FTIR measurement period, three-dimensional sonic anemometers (CSAT-3, Campbell Scientific, Logan, Utah; and HS-50, Gill Instruments Ltd., Lymington, UK). were used to measure $w$ at eight heights $(0.5,1.9,11.1,18.7,27.2,35.0,43.5,70.0 \mathrm{~m})$ within and above the canopy. The data from the sonic anemometers were used to calculate profiles of $T_{E}$ using Eq. 6 and thence $T_{L}$ from (5) assuming $\beta=1$, as well as vertical profiles of $H$.

Also during this period, $\mathrm{CO}_{2}$ fluxes at the ground were measured using an infra-red gas analyser attached to ten automated, pneumatic open-and-close chambers (Fest et al. 2008) and these were compared to $\mathrm{CO}_{2}$ fluxes from the ground derived from air temperature and soil moisture data via a correlation developed from earlier static chamber measurements using absorption of $\mathrm{CO}_{2}$ by soda lime (Keith and Wong 2006).

\subsection{SVAT Model}

Source/sink distributions of heat, water vapour and $\mathrm{CO}_{2}$ were predicted using a multi-layered canopy model originally developed by Leuning et al. (1995), with improvements described by Wang and Leuning (1998) and Haverd et al. (2007). The core of the model is a leaflevel sub-model that couples stomatal conductance, photosynthesis and energy partitioning in response to radiation absorption, temperature and water vapour pressure deficit at leaf surfaces (Leuning et al. 1995). Four key parameters in the sub-model were estimated by minimizing a cost function of residuals between predicted and net fluxes (of $H, \lambda E$ and $F_{c}$ ) measured above the canopy.

The radiation sub-model, based on the approximations of Goudriaan and van Laar (1994), was used to calculate the rates of radiation absorption by sunlit and shaded leaves and by the soil in the visible, near-infrared and thermal wavebands. The leaf angle distribution parameter in the sub-model for radiation transfer within the canopy (Sellers 1985; Wang and Leuning 1998) was optimized independently, to minimize the residuals between model estimates and measurements of $P_{\text {gap }}$, the probability of a direct beam not being intercepted by vegetation, at a range of view angles and heights. The mean vertical leaf area density profile that was obtained by Jupp et al. (2008) from $P_{\text {gap }}$ using in-canopy Lidar measurements was a direct input to the model, as were local hourly meteorological data, and local hourly measured vertical profiles of temperature, water vapour and $\mathrm{CO}_{2}$ concentrations.

Respiration rates of soil and vegetation were calculated using functional relationships between respiration and soil and air temperatures obtained from chamber measurements (Keith and Wong 2006). Latent and sensible heat fluxes at the soil surface were calculated by solving the conservation equations for vertical, coupled heat and moisture fluxes in the soil, using a numerical scheme that is an extension of the fast numerical solution of the Richards' Equation by Ross (2003). Treatment of run-off, infiltration and ponding followed 
the approach of Ross (2003) and heat and water vapour transport through the litter layer was modelled similarly to Ogée and Brunet (2002).

\section{Results}

\subsection{Concentration Profiles: Filtering and Averaging}

A one-dimensional, steady state transport model was used in the current analysis. Consequently, we restricted model/measurement comparisons to times when the flow above and below the canopy was fully coupled, and hence when the advection and changes in storage terms in the mass balance of the control volume below the flux measurement height were negligible. Our criterion for fully coupled flow is that the gradient Richardson number, $R i \leq 1.0$ at any height below $70 \mathrm{~m}$, where $R i=(g / \bar{\theta})(\partial \bar{\theta} / \partial z) /(\partial \bar{u} / \partial z)^{2}$ (Kaimal and Finnigan 1993). (Here $g$ is the gravitational constant.) $R i$ was evaluated from mean hourly, 8-point vertical profiles of horizontal wind speed and potential temperature, $\theta$, measured at $0.55,4.8,10.6$, $26.0,34.7,42.4,55.7$ and $70.0 \mathrm{~m}$. Partial derivatives were estimated by differentiating cubic spline interpolants of the profiles. After filtering, $44 \mathrm{H}_{2} \mathrm{O}, 33 \mathrm{CO}_{2}$ and $62 \theta$ profiles remained for analysis. These figures represent approximately $30 \%$ of the respective daytime datasets.

The quasi-instantaneous individual difference profiles of potential temperature, water vapour and $\mathrm{CO}_{2}$ concentrations are shown in Fig. 2, together with their corresponding ensemble-average hourly profiles. Individual $\mathrm{CO}_{2}$ and $\mathrm{H}_{2} \mathrm{O}$ concentration profiles are less smooth than the potential temperature profiles and this may be attributable to insufficiently long averaging times for each point on the $\mathrm{CO}_{2}$ and $\mathrm{H}_{2} \mathrm{O}$ profiles. We therefore choose to work with hourly profiles averaged over several days, which considerably increases the total measurement time for each profile point. Data from rainy days have been filtered out to reduce day-to-day variability between the source/sink distributions for a given hour of day. We observed agreement within $95 \%$ confidence limits between water vapour profiles obtained from the FTIR instrument and those measured routinely using a LI6262 analyser with an independent sampling system, which measures the concentrations for $10 \mathrm{~s}$ at each of nine heights, 16 times per hour. This high level of agreement suggests that the total averaging time for each of the hourly ensemble average FTIR profiles is sufficient.

\subsection{Foliage Area Volume Density (FAVD) Distribution and $P_{g a p}$}

In a separate study (Jupp et al. 2008), the gap probability for penetration of direct beam radiation through the canopy was determined as a function of height and view angle at eight sites within the flux footprint surrounding the mast using Echidna ${ }^{\mathrm{TM}}$, a ground-based lidar that scans a full hemisphere from a point $2 \mathrm{~m}$ above the canopy floor. These measurements were used to derive foliage area volume density (FAVD) profiles for each site. The mean FAVD profile plus and minus one standard error $\left(\overline{F A V D}_{+}\right.$and $\left.\overline{F A V D}_{-}\right)$, is reproduced in Fig. 3a. In this work, the mean $P_{\text {gap }}$ profiles (averaged over the eight sites from $z=2 \mathrm{~m}$ upwards) were compared with predictions of a simple model of $P_{\text {gap }}$ :

$$
P_{\text {gap }}\left(\theta_{v}, \xi\right)=\exp \left[-G\left(\theta_{v}\right)\left(\xi_{z=2 m}-\xi\right) / \cos \theta_{v}\right],
$$

where $\theta_{v}$ is the upward-looking view angle, $G\left(\theta_{v}\right)$ is the unit area projection of leaves in the direction of the beam, $\xi$ is cumulative foliage area from the top of the canopy downwards, as obtained from the mean FAVD profile. $G\left(\theta_{v}\right)$ depends on the leaf angle distribution and here we use the empirical formulation of Sellers (1985): 


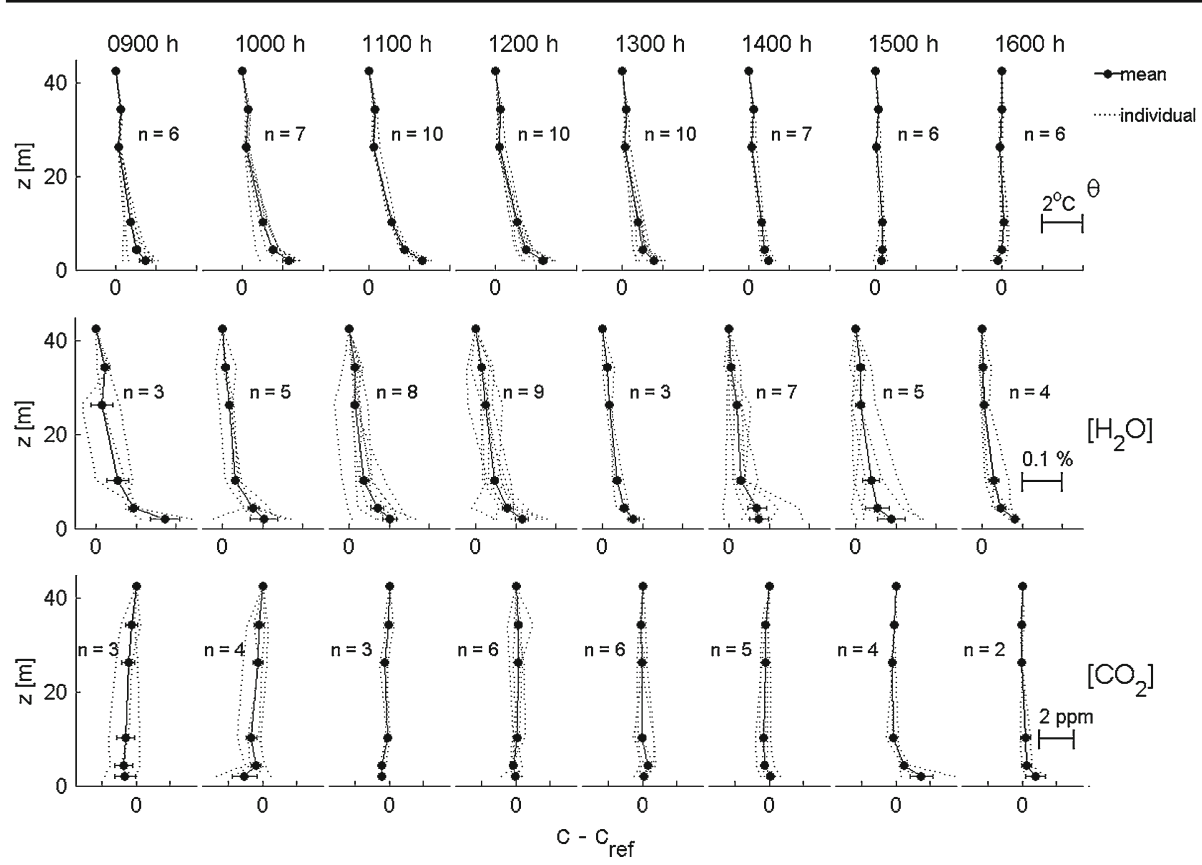

Fig. 2 Individual concentration profiles (relative to concentration at canopy top) at times when $R i<1$, and corresponding hourly mean profiles

$$
G\left(\theta_{v}\right)=\phi_{1}+\phi_{2} \cos \left(\theta_{v}\right)
$$

where $\phi_{1}=0.5-0.633 \chi_{L}-0.33 \chi_{L}^{2}$ and $\phi_{2}=0.877\left(1-2 \phi_{1}\right)$ and $\chi_{L}$ is a function characterising the departure of leaf angles from a spherical distribution, taking values of zero for spherically arranged leaves, +1 for horizontal leaves and -1 for vertical leaves. The leaf angle parameter, $\chi_{L}$, was treated as an adjustable parameter, and a value of -0.4 gave the best agreement between measured $P_{g a p}$ and the predictions of Eq. 10. This value was then held fixed for use in the multilayer SVAT model, where $G\left(\theta_{v}\right)$ is required for the evaluation of radiation extinction coefficients. $P_{\text {gap }}$ measurements for two selected view angles and corresponding predictions of Eq. 10 are shown in Figs. $3 \mathrm{~b}$ and c. The standard error in the measured mean $P_{\text {gap }}$ profiles is much larger than the model/measurement discrepancy. Therefore we expect the uncertainty in the radiation fluxes predicted by the SVAT model to be dominated by uncertainty in the mean FAVD profile (due to horizontal heterogeneity), and not by model error. We also note here that the FAVD profile does not extend below the instrument height of $2 \mathrm{~m}$. Below $2 \mathrm{~m}$, there is an understorey of patchy shrubs and grasses with a total leaf area index of $1.5 \pm 0.4$, as determined from biomass measurements (H. Keith, personal communication, 2006).

\subsection{Fluxes of Absorbed Radiation, Sensible Heat, Latent Heat and $\mathrm{CO}_{2}$}

Above-canopy fluxes of net absorbed radiation, sensible heat, latent heat and $\mathrm{CO}_{2}$ were simulated using three different leaf area density profiles: $\overline{F A V D}_{\overline{F A V D}}$ and $\overline{F A V D}_{-}$, corresponding to the mean profile (averaged over eight sites) and one standard error either side of this profile. For each case, non-linear parameter estimation was used to minimize a 

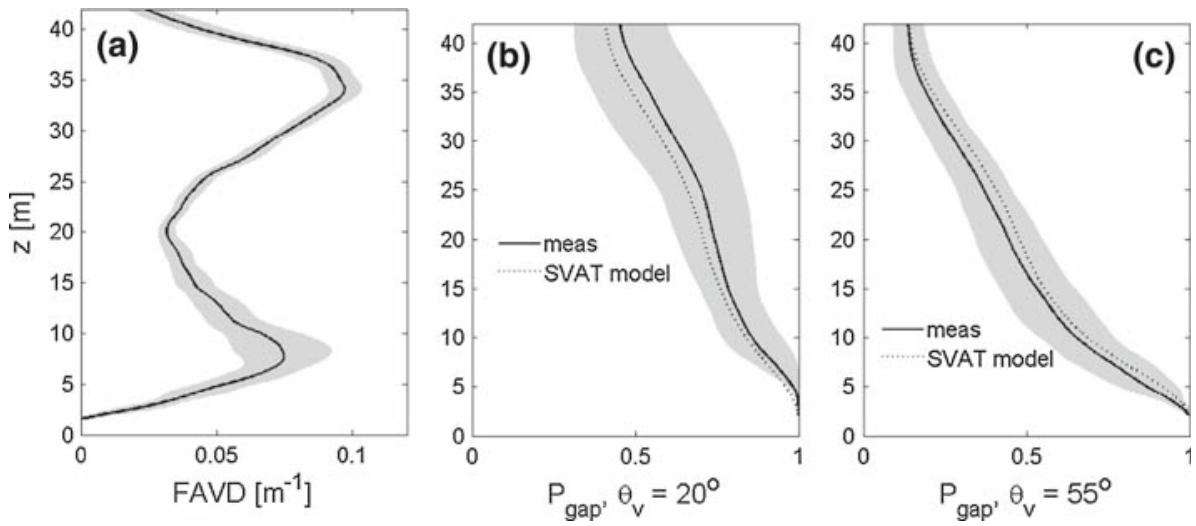

Fig. 3 a Foliage area volume density derived from $P_{\text {gap }}$ measurements, $\mathbf{b}$ and $\mathbf{c}$ Gap probabilities as a function of height for two upward-looking view angles. Shading represents the standard error on mean measured $P_{g a p}$, as determined from variance of $P_{\text {gap }}$ at eight sites. Model calculations correspond to Eq. 10, with optimised leaf angle distribution parameter. Shading corresponds to standard error, based on variance of data from eight sites

Table 1 Optimised parameter values for SVAT model with three different FAVD profiles

\begin{tabular}{|c|c|c|c|c|}
\hline Parameter & $\overline{F A V D}$ & $\overline{F A V D}_{-}$ & $\overline{F A V D}_{+}$ & Units \\
\hline$V_{\text {cmax }, 0}$ & 73 & 78 & 72 & $\mu \mathrm{molCO} \mathrm{CO}_{2} \mathrm{~m}^{-2} \mathrm{~s}^{-1}$ \\
\hline$a_{1}$ & 5.7 & 5.9 & 6.5 & - \\
\hline$D_{s, 0}$ & 1.0 & 1.0 & 0.8 & $\mathrm{kPa}$ \\
\hline$\alpha$ & 0.10 & 0.10 & 0.09 & $\mathrm{~mol} \mathrm{e} \mathrm{mol}^{-1}$ quanta \\
\hline
\end{tabular}

cost function of residuals between model and observed fluxes, by optimizing the following parameters of the leaf-level model: $V_{\mathrm{cmax}, 0}, a_{1}, D_{0}$, and $\alpha$ (Leuning 1995). These represent respectively: the maximum catalytic activity of the photosynthetic enzyme Rubisco at $293 \mathrm{~K}$; a parameter relating stomatal conductance to intercellular $\mathrm{CO}_{2}$ concentration at saturating irradiance; a coefficient that determines the modelled sensitivity of the stomata to humidity deficit at the leaf surface; and the quantum yield of whole-chain electron transport. Table 1 shows that the optimised values of $V_{\mathrm{cmax}, 0}, D_{0}$, and $\alpha$ are quite insensitive to the uncertainties in the FAVD profile, while increasing FAVD by one standard deviation causes $a_{1}$ to increase by only $14 \%$.

The predicted net daytime fluxes at the top of the canopy (for the mean leaf area density profile) are shown in Fig. 4 as hourly averages over 12 rain-free days. Corresponding measurements are also shown. Uncertainties in the predicted and measured fluxes are standard errors in the mean and arise from day-to-day variation in the fluxes due to variable meteorological conditions and soil moisture. The predicted and measured fluxes generally agree within $95 \%$ confidence limits, with a few exceptions. In particular, the sensible heat flux is overestimated by about $50 \mathrm{Wm}^{-2}$ at $1500 \mathrm{~h}$ local time, and the latent heat flux is underestimated by a similar amount at $1200 \mathrm{~h}$ and $1400 \mathrm{~h}$. 

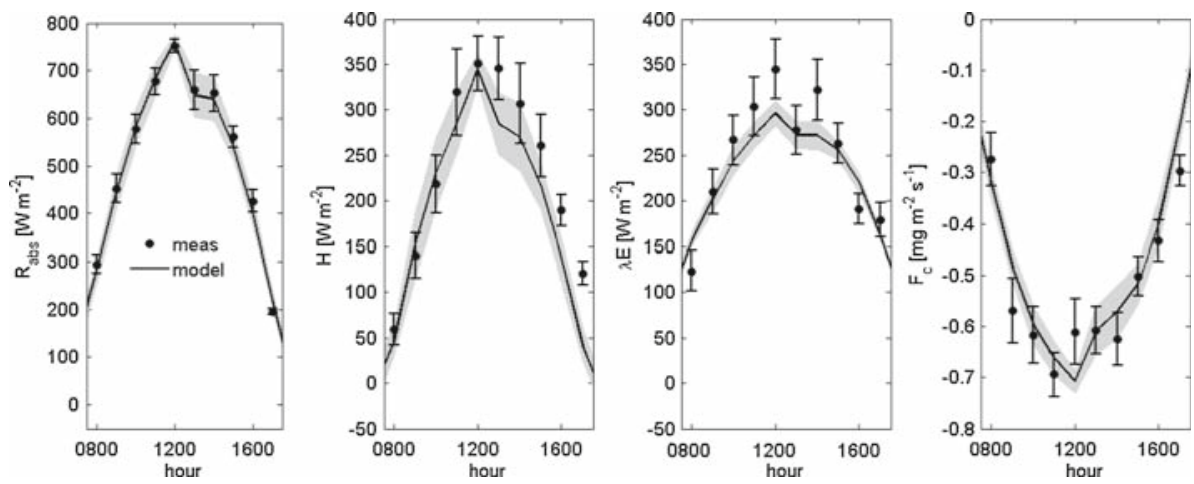

Fig. 4 Hourly above-canopy fluxes of net radiation, sensible heat, latent heat and $\mathrm{CO}_{2}$, averaged over 10 days. Error bars on measurements represent standard errors on mean, with contributions from measurement noise and day-to-day meteorological variability. Model fluxes are averaged over the same 10 days and are obtained from the optimised SVAT model, with the mean FAVD profile. The shaded area represents standard errors on the mean calculated fluxes, due to day-to-day meteorological variability

\subsection{Vertical Source/Sink Distributions}

Predicted mean midday vegetation source/sink distributions plus and minus one standard error $\left(\bar{S}_{+}\right.$and $\left.\bar{S}_{-}\right)$, for net absorbed radiation, sensible heat, latent heat and $\mathrm{CO}_{2}$, integrated over each 2-m layer are shown in Fig. 5. Standard errors on the source/sink distributions for vegetation and soil were calculated as the quadratic sum of standard errors due to uncertainties in the net flux and uncertainties in the leaf area profile (and hence radiation fluxes). In the case of $\mathrm{CO}_{2}$, uncertainty in the measured ground $\mathrm{CO}_{2}$ flux is also included. Standard errors due to uncertainties in the net flux were calculated as the difference between modelled and measured net flux, distributed over the profile in proportion to the vertical distribution of the calculated net radiation absorbed at each level, $R_{a b s}$. Standard errors due to uncertainties in the FAVD profile were taken as $\max \left\{\left|S_{\overline{F A V D}}-S_{\overline{F A V D_{+}}}\right|,\left|S_{\overline{F A V D}}-S_{\overline{F A V D}}\right|\right\}$. The standard error in the ground $\mathrm{CO}_{2}$ flux was set to $0.04 \mathrm{mg} \mathrm{CO}_{2} \mathrm{~m}^{-2} \mathrm{~s}^{-1}$, corresponding to the maximum absolute difference between estimates of $\mathrm{CO}_{2}$ ground fluxes from two sets of independent chamber measurements. (Keith and Wong 2006; Fest et al. 2008)

Hourly partitioning of the fluxes between soil and vegetation is shown in Fig. 6, with the shaded area representing the errors, as discussed above. According to the model, the canopy absorbed about $70 \%$ of the total net radiation. Sensible heat fluxes were partitioned roughly equally between the vegetation and soil, whereas latent heat fluxes from the soil were $<10 \%$ of the total. The soil was predicted to be a source of $\mathrm{CO}_{2}$ of about $0.1 \mathrm{mg} \mathrm{CO}_{2} \mathrm{~m}^{-2} \mathrm{~s}^{-1}$ and the canopy a sink ranging between 0.8 and $0.4 \mathrm{mg} \mathrm{CO}_{2} \mathrm{~m}^{-2} \mathrm{~s}^{-1}$. Canopy fluxes of all quantities peaked around $1100 \mathrm{~h}$.

Model predictions of the source distribution of $H$ were tested by comparing measured vertical profiles of $H$ (obtained from the array of sonic anemometers mounted on the mast) with corresponding model predictions. Results are shown in Fig. 7 as ensemble averages over sunny days during the measurement period $(n=5)$. Error bars on the measurements represent standard errors $(\sigma / \sqrt{n})$ due to day-to-day variability. The standard error in the model predictions (shaded areas) was calculated as the quadratic sum of standard errors due to uncertainties in leaf area profile and day-to-day variability. Good model/measurement agreement at $z=0$ indicates that the predicted soil heat flux is consistently accurate 

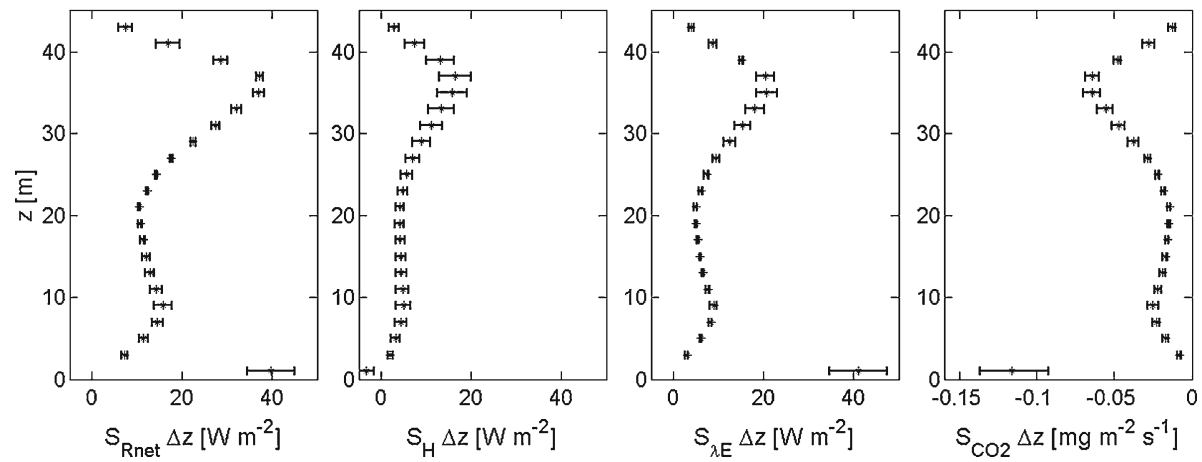

Fig. 5 Predicted midday vertical source/sink distributions for the vegetation only, averaged over 10 days. Each point represents a source density, integrated over the vertical thickness of the layer $(\Delta z=2 \mathrm{~m})$. Error bars are standard errors on the mean, with contributions from uncertainties in the FAVD profile, the net above-canopy flux, ground $\mathrm{CO}_{2}$ flux
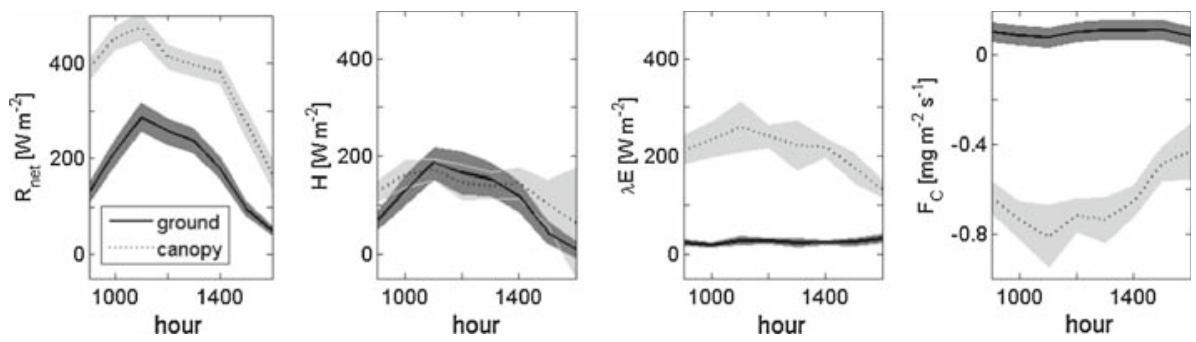

Fig. 6 Predicted hourly distribution of net fluxes between ground and vegetation, averaged over 10 days. Shaded areas represent standard errors on the mean, with contributions from uncertainties in the FAVD profile, the net above-canopy flux, ground $\mathrm{CO}_{2}$ flux

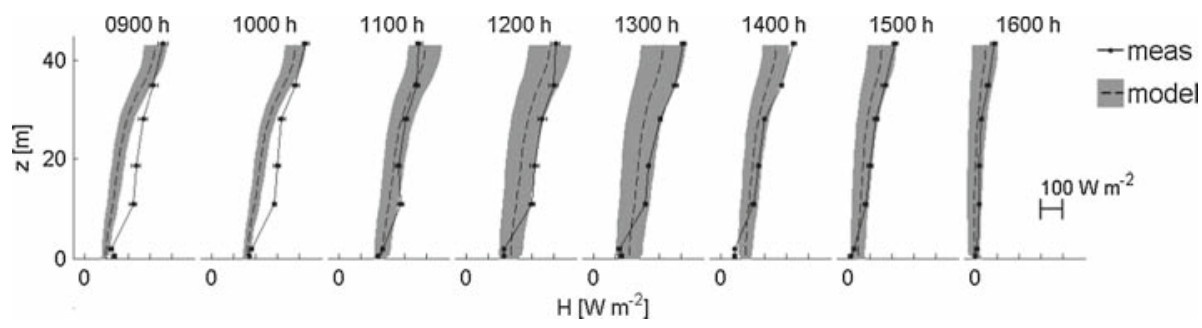

Fig. 7 Predicted and observed hourly vertical sensible heat profiles, averaged over five days. Shaded areas represent standard errors on the mean, with contributions from uncertainties in the FAVD profile and the day-to-day variability. Error bars on the measurements represent the stand error in the mean measured profiles

(to within the $95 \%$ confidence limits of $<50 \mathrm{~W} \mathrm{~m}^{-2}$ shown in Fig. 6). The canopy heat source distribution is also generally well represented by the model, except at $0900 \mathrm{~h}$ and $1000 \mathrm{~h}$, when the measurements indicate that the lower $10 \mathrm{~m}$ of the canopy is a greater sensible heat source than predicted by the model. 

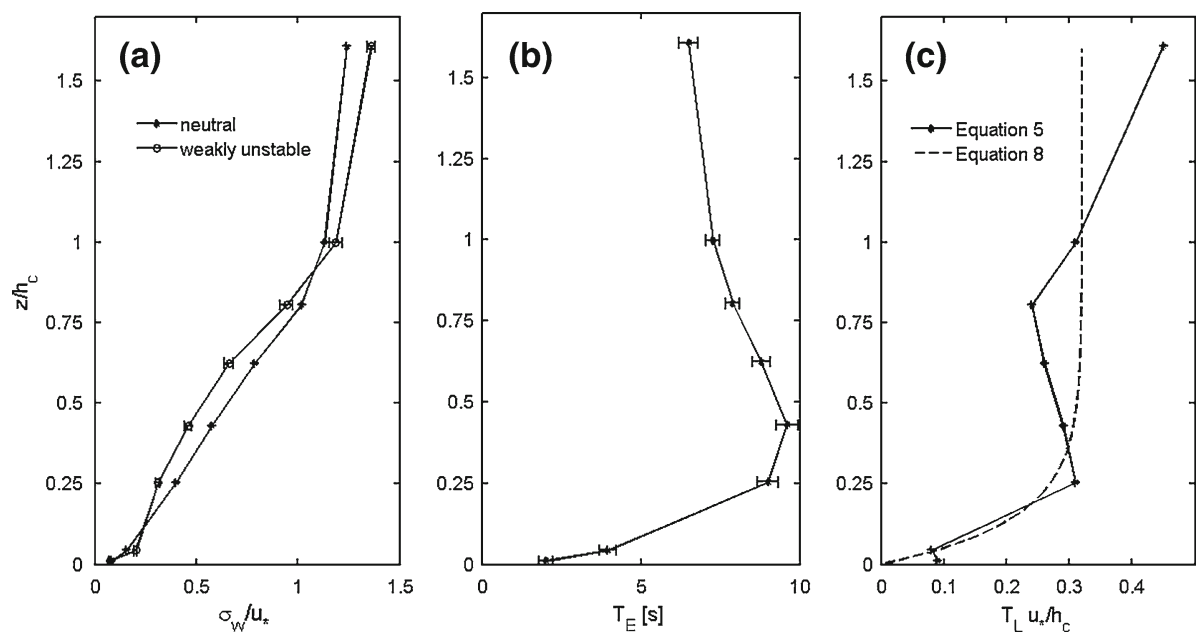

Fig. 8 Turbulence statistics from measurements: a $\sigma_{w} / u_{*}$ for neutral and weakly unstable stratification, b Eulerian time scale, $T_{E}$, for neutral stratification (Eq. 6), c Lagrangian time scale calculated from $T_{E}$ (Eq. 5) with $\beta=1$ ), and parameterised using Eq. 8, with $c_{1}=7.32$ and $c_{2}=0.32$

\subsection{Turbulence Statistics}

Time series of $w$ measured at eight heights were sorted according to atmospheric stability at the top of the mast and used to generate vertical profiles of $\sigma_{w}$ and $T_{L}$ using Eqs. 5 and 6 with $\beta=1$. The selected profiles coincided with near-neutral $\left(-0.05<\left(h_{c}-d\right) / L<0.05\right)$ or weakly unstable $\left(-0.5<\left(h_{c}-d\right) / L<-0.05\right)$ stratification, as defined by the Obukhov length, $L=-u_{*}^{3} \bar{\theta} /\left(k g \overline{w^{\prime} \theta^{\prime}}\right)$, with $u_{*}$ and the vertical kinematic heat flux, $\overline{w^{\prime} \theta_{v}^{\prime}}$, taken from measurements at $70 \mathrm{~m}$. The selected vertical profiles of $\sigma_{w}$ are shown in Fig. 8a and these were used as direct inputs to the dispersion model. Estimates of $T_{E}$ for weakly unstable and nearneutral conditions are indistinguishable at the $95 \%$ confidence level and only the near-neutral profiles of $T_{E}$ and $T_{L} u_{*} / h_{c}$ are shown in Fig. $8 \mathrm{~b}$ and c respectively. The function proposed by Styles et al. (2002) (Eq. 8) was fitted to the near-neutral profile of $T_{L}=\left(\bar{u} T_{E}\right) / \sigma_{w}$, with fitted coefficients taking values of $c_{1}=7.32$ and $c_{2}=0.32$. (These are the 'prior' coefficients used in Sect. 4 below.)

\section{Predicted Concentration Profiles and Optimized $T_{L}$}

Within-canopy concentration profiles were predicted using Eq. 1 with the $S_{j}$ profiles from the multilayer SVAT model, and then averaged to produce hourly mean profiles corresponding to the mean measured profiles in Fig. 2. The dispersion matrix $D_{i j}$ was computed using hourly values of $u_{*}$ and either of the $\sigma_{w} / u_{*}$ profiles in Fig. 8a, depending on whether atmospheric stability is near-neutral or weakly unstable. $\mathrm{T}_{L} u_{*} / h_{c}$ was estimated using both the Styles et al. (2002) parameterisation (Eq. 8) with prior and optimized coefficients $c_{1}$ and $c_{2}$, and the MW model (Eq.9) with prior and optimised coefficient $A_{2}$. The prior value of $A_{2}$ was set to 0.6, as suggested by Massman and Weil (1999). Henceforth we refer to the Styles et al. (2002) parameterisation of $T_{L}$ using prior and optimized coefficients as $T_{L, p, S}$ and 
$T_{L, \text { opt }, S}$, respectively, and the MW formulation of $T_{L}$ using prior and optimized values of $A_{2}$ as $T_{L, p, M W}$ and $T_{L, o p t, M W}$.

Coefficients in the two parameterizations of $T_{L}$ were optimized using nonlinear parameter estimation. An additional parameter, $x_{\lambda E}$, was introduced because model predictions of the Bowen ratio at the soil were not constrained by measurements other than the concentration profiles. This contrasts with $\mathrm{CO}_{2}$, where chamber measurements of $\mathrm{CO}_{2}$ fluxes at the soil surface were available. Specifically, the latent heat flux at the soil was set to $\left(1+x_{\lambda E}\right) \lambda E_{\text {soil }}$ where $\lambda E_{\text {soil }}$ is the SVAT model output value, and the prior estimate of $x_{\lambda E}$ was set to zero. The parameter estimation procedure minimizes a cost function defined as:

$$
\Phi=\sum \Phi_{c}
$$

with $c=\theta, \mathrm{H}_{2} \mathrm{O}, \mathrm{CO}_{2}$ and where the partial cost is:

$$
\Phi_{c}=\sum_{j=1}^{m}\left(w_{j} r_{j}\right)^{2}
$$

with $r_{j}$ the residual between observed and measured mean hourly concentration difference, relative to the measured mean concentration difference:

$$
r_{j}=\frac{\left(\overline{c_{i}-c_{r e f}}\right)_{k, o b s}-\left(\overline{c_{i}-c_{r e f}}\right)_{k, \text { mod }}}{\left(\overline{c_{i}-c_{r e f}}\right)_{k, o b s}}
$$

for each of the five in-canopy heights of each of the eight hourly mean profiles (giving $\mathrm{m}=40$ ). Here $w_{i}$ is the weighting given to each mean-profile point to account for uncertainty in both the observation and the model:

$$
w_{j}=\frac{\sqrt{n_{k}}}{\sqrt{\sigma_{j, o b s}^{2}+\sigma_{j, \text { mod }}^{2}}} .
$$

In Eqs. 13-15, $i$ refers to an individual height on an individual profile, $j$ refers to an individual height on a mean hourly concentration difference profile, $k$ refers to a mean hourly profile, and $n_{k}$ is the number of ensemble members contributing to each of the $k$ hourly mean profiles. The Gauss-Levenberg-Marquardt method was used in the optimization process, as implemented in the model-independent parameter estimation software, PEST (Doherty 1999).

Table 2 lists the partial and total values of the cost functions and corresponding parameter values for predictions using the Styles et al. (2002) parameterisation of $T_{L}\left(T_{L, p, S}, T_{L, o p t, S}\right)$. Optimization of the coefficients in this parameterisation reduces the values of all three partial cost functions, and the total cost function value is reduced by $72 \%$. Corresponding predictions and observations of concentration profiles are shown in Figs. 9 and 10, with outer edges of the shaded areas corresponding to predictions using $\bar{S}_{+}$and $\bar{S}_{-}$. The optimization decreases $c_{1}$ and increases $c_{2}$ (Table 2), which has the effect of increasing the maximum value of $T_{L}$, and increasing the height below which it decreases towards zero. The correspondingly enhanced turbulent mixing leads to a decrease in the magnitude of the predicted concentration gradients within the canopy that are needed to match the observations. The optimised profile predictions (Fig. 10) mostly agree with observations at the 95\% confidence level. The exceptions are:

(1) the $0900 \mathrm{~h}$ water vapour profiles: here underprediction of $c-c_{r e f}$ by up to $0.1 \%$ may be due to the SVAT model's failure to account for the formation and evaporation of dew. 

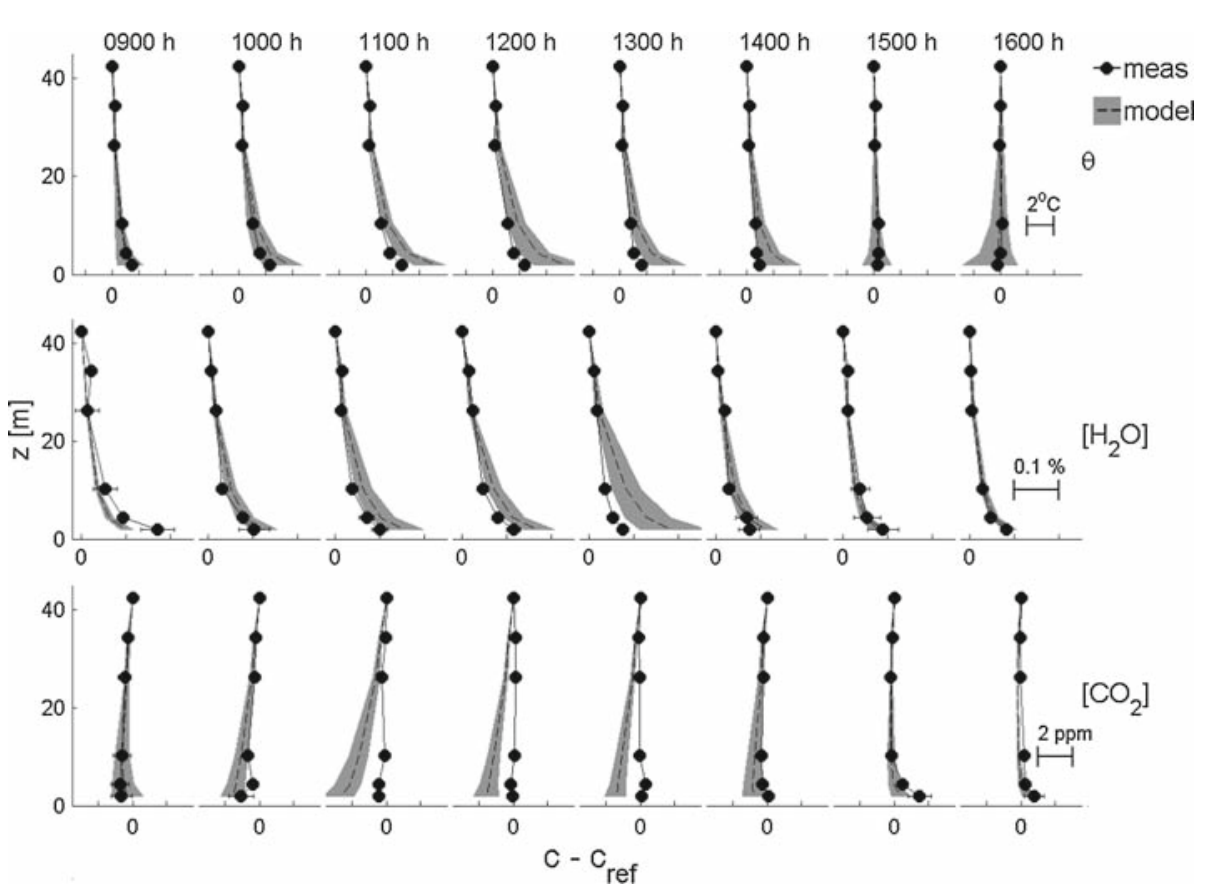

Fig. 9 Mean measured profiles (as shown in Fig. 2) and corresponding predicted concentration profiles using $\bar{S}$ and $T_{L, p, S}$, which was constructed by optimising Eq. 8 against estimates of $T_{L}$ from Eq. 5 . Boundaries of the shaded areas correspond to profiles predicted using $\bar{S}_{+}$and $\bar{S}_{-}$
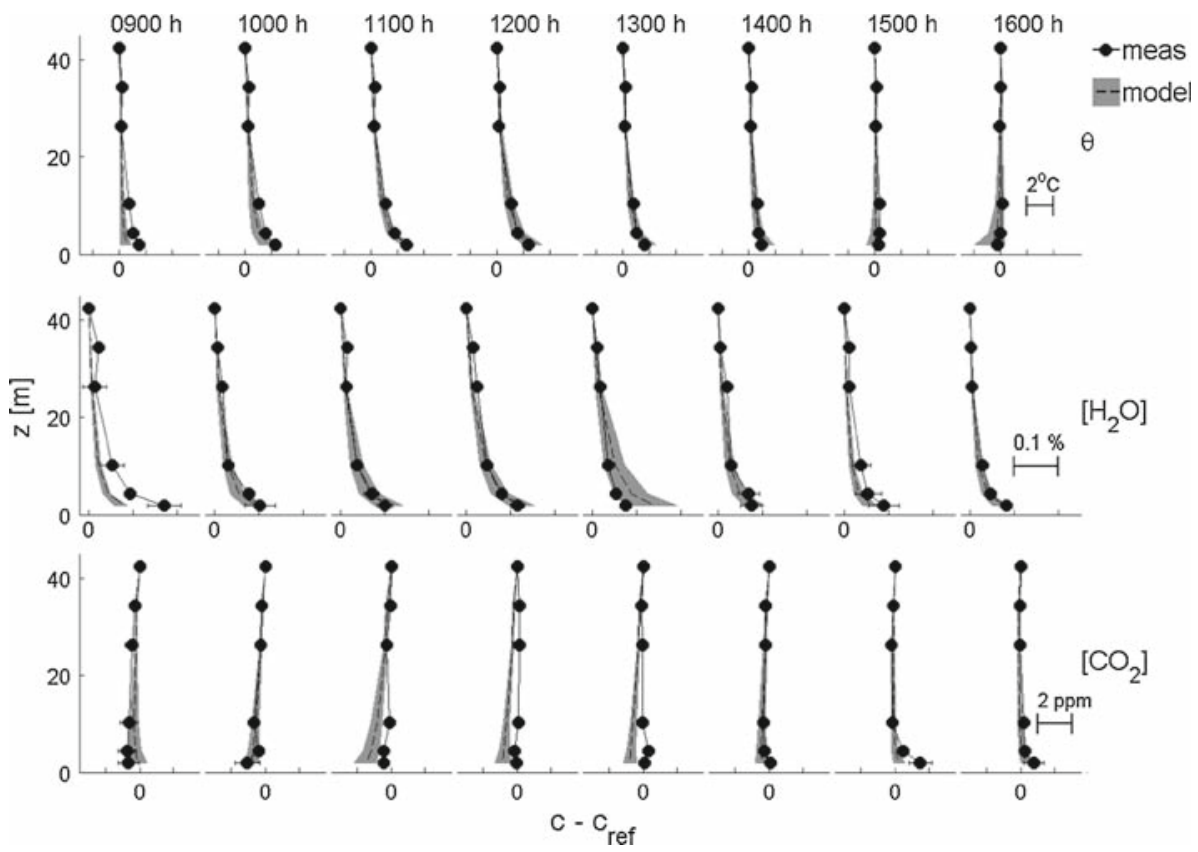

Fig. 10 As for Fig. 9, but with concentration profiles predicted using $T_{L, \text { opt }, S}$ 
Table 2 Partial and total cost functions and optimised parameter values for coefficients in the $T_{L}$ parameterisations and the parameter for adjusting the latent heat flux at the soil

\begin{tabular}{llllll}
\hline & & $T_{L, p, S}$ & $T_{L, \text { opt }, S}$ & $T_{L, p, M W}$ & $T_{L, \text { opt }, M W}$ \\
\hline Cost & $\Phi_{\theta}$ & 345 & 165 & 95 & 141 \\
& $\Phi_{\mathrm{H}_{2} \mathrm{O}}$ & 80 & 48 & 65 & 60 \\
& $\Phi_{\mathrm{CO}_{2}}$ & 397 & 123 & 337 & 253 \\
\multirow{4}{*}{ Parameters } & $\Phi$ & 822 & 336 & 497 & 454 \\
& $c_{1}$ & 7.32 & $4.86 \pm 1.52$ & & \\
& $c_{2}$ & 0.32 & $0.66 \pm 0.10$ & & 0.6 \\
& $\mathrm{~A}_{2}$ & & & $0.16 \pm 0.08$ \\
& $\mathrm{x}_{\lambda E}$ & 0.0 & $0.12 \pm 0.04$ & 0.0 & $0.15 \pm 0.09$ \\
\hline
\end{tabular}

(2) the $1100-1300 \mathrm{~h}$ and $1500 \mathrm{~h} \mathrm{CO}$ profiles: here the model predicts in-canopy $\mathrm{CO}_{2}$ concentrations that are up to $1 \mathrm{ppm}$ lower than observed. The $\mathrm{CO}_{2}$ ground flux is measured, and conservative error estimates are factored into the source/sink distribution errors, which are reflected by the shaded areas around the profile predictions. The same is true for the net $\mathrm{CO}_{2}$ flux. It is likely that the discrepancy arises from errors in the predictions in the $\mathrm{CO}_{2}$ sink distribution, which are not attributable to uncertainties in radiation fluxes. A possible explanation for such errors is that, while the model allows photosynthetic parameters to vary with canopy depth, no account is taken for different age classes and species in the forest.

Optimisation of $A_{2}$ in the MW parameterization of $T_{L}$ lowers the value of all partial cost functions and of the total cost function by $9 \%$ compared to the simulation using the prior value of $A_{2}$ (Table 2), but the total cost using the MW formulations is still 35\% higher than that obtained using the optimised Styles et al. (2002) parameterization. The poorer performance of the MW parameterization is also seen by comparing model/measurement agreement in Figs. 10 and 11. In particular, from $1000 \mathrm{~h}$ to $1300 \mathrm{~h}$, the elevated measured potential temperatures close to the ground are reproduced well by the predictions using $T_{L \text {,opt }, S}$ (Fig. 10), but are underestimated by the predictions using $T_{L, o p t, M W}$ (Fig. 11). This is seen in the lower values for all partial cost functions for the Styles et al. (2002) parameterisation compared to that of MW (Table 2).

Prior and optimized vertical profiles of $T_{L}$ for the MW and Styles et al. parameterizations are shown in Fig. 12a and b. Shaded areas represent \pm 1 standard deviation about the mean optimised profiles, calculated as the quadratic sum of: (1) standard deviation in $T_{L}$ attributable to variances and covariances in the estimated parameters, and (2) $\max \left\{\left|T_{L, \bar{S}}-T_{L, \bar{S}_{+}}\right|\right.$, $\left.\left|T_{L, \bar{S}}-T_{L, \bar{S}_{-}}\right|\right\}$, i.e. the maximum of the absolute differences between $T_{L}$ derived using $\bar{S}$, and $T_{L}$ derived using $\bar{S}_{+}$and $\bar{S}_{-}$. In Fig. 12a, we see that, in the case of the optimised Styles et al. (2002) parameterisation, $T_{L}(z) u_{*} / h_{c}$ decreases from a maximum value of 0.67 at $z=h_{c}$ to 0.57 at $z=0.4 h_{c}$ and drops rapidly to zero at the ground. In contrast the optimised MW parameterisation (Fig. 12b) predicts $T_{L}(z) u_{*} / h_{c}$ to have a minimum value of 0.38 at $z=h_{c}$, increasing to 0.57 at $z=0.4 h_{c}$ and rising further to 1.6 at the ground. In both cases the normalised value of $T_{L}$, and hence the degree of turbulent mixing, is larger than the prior estimates and the estimates assumed in earlier studies (see Fig. 1). The result of the optimised Styles parameterisation, that $T_{L}(z) u_{*} / h_{c}=0.67 \pm 0.11$ at $z=h_{c}$, is qualitatively consistent with the presence of a roughness sublayer (RSL), which enhances the far-field diffusivity above that predicted from extrapolation down from the inertial sublayer (ISL) (Harman and Finnigan 2007). More specifically, it carries an implication for the depth of the 

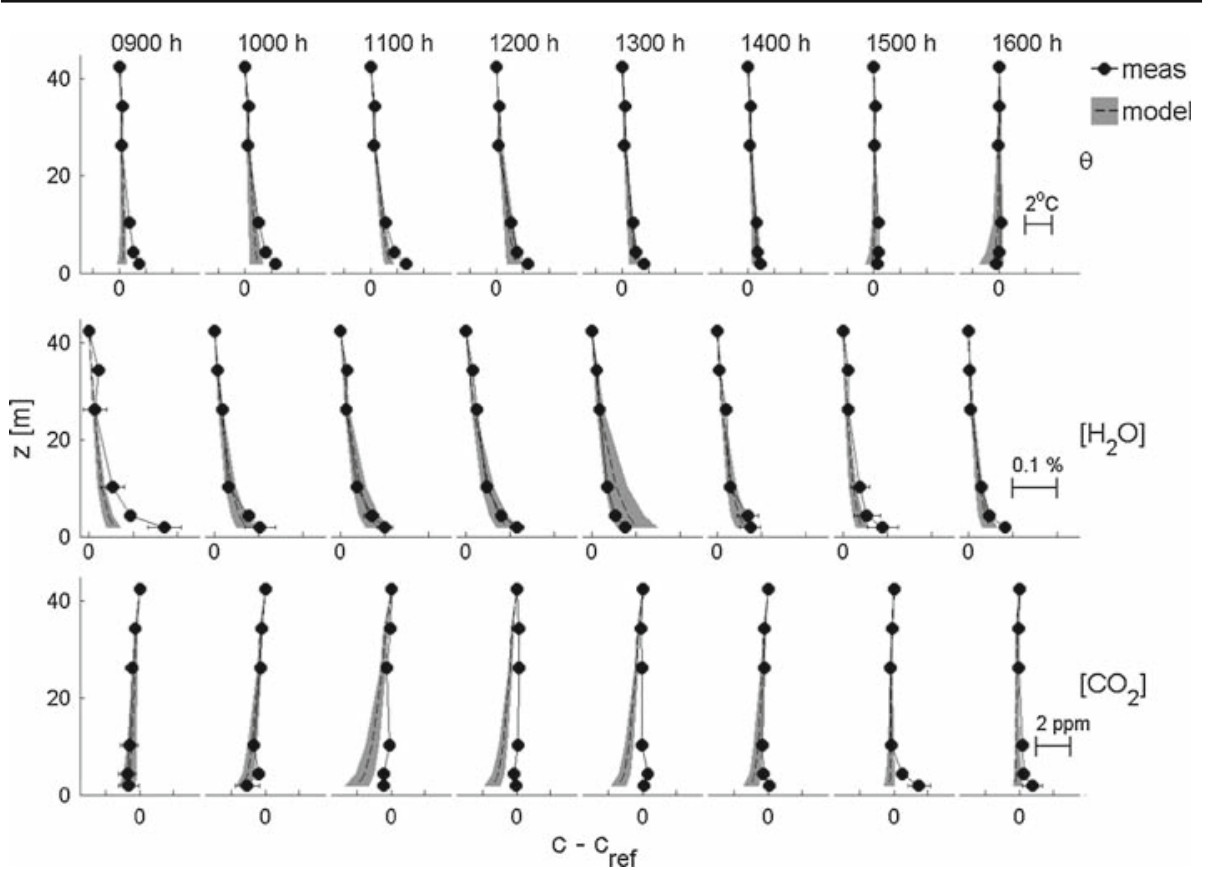

Fig. 11 As for Fig. 9, but with concentration profiles predicted using $T_{L, \text { opt }, M W}$
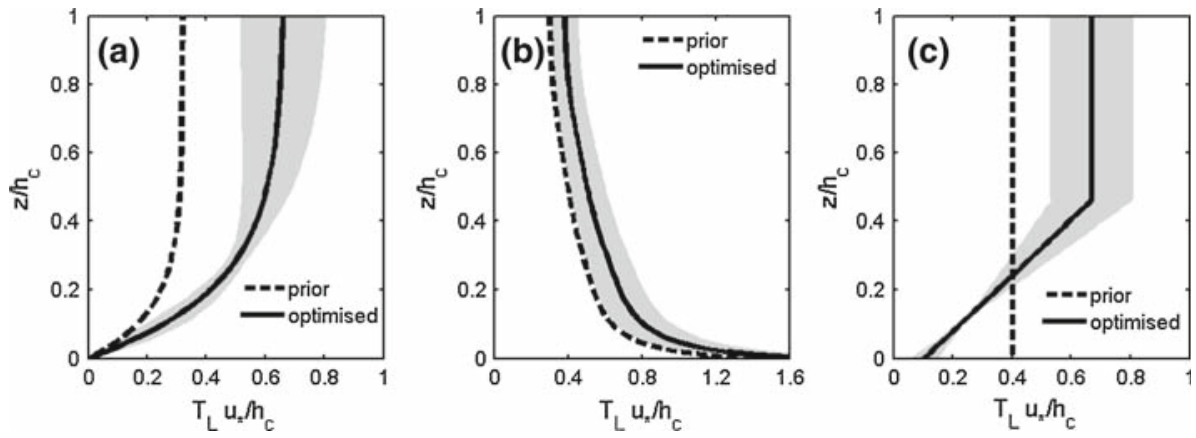

Fig. 12 Prior and optimised estimates of $T_{L}: \mathbf{a} T_{L, p, S}$ and $T_{L, o p t, S}, \mathbf{b} T_{L, p, M W}$ and $T_{L, o p t, M W}, \mathbf{c}$ Eq. 17

RSL: let $z_{R}$ be the height of the upper limit of the RSL (and hence the lower limit of the ISL). Rearranging Eq. 7 to solve for $z_{R}$ gives

$$
\frac{\left(z_{R}-d\right)}{h_{c}}=\frac{T_{L} u_{*}}{h_{c}} \frac{\left(\sigma_{w} / u_{*}\right)^{2}}{k},
$$

and assuming the value of $T_{L}(z) u_{*} / h_{c}=0.67$ at $z=h_{c}$ to be a lower bound for $T_{L}(z) u_{*} / h_{c}$ in the RSL $\left(h_{c}<z<z_{R}\right)$, and with $d=0.8 h_{c}$ and $\sigma_{w} / u_{*}=1.25$, one obtains $z_{R} \geq 3.4 h_{c}$. This is deeper than previous estimates of $z_{R} \approx 2 h_{c}$ (Raupach 2001).

The MW and Styles parameterisations predict a very different behaviour of $T_{L}$ close to the ground. As discussed above, the use of $T_{L, o p t, S}$ leads to a lower value of the cost function 
and more accurate simulation of the concentration profiles close to the ground compared to the use of $T_{L, o p t, M W}$ for all three scalars considered in this study. These results support the use of a diminishing $T_{L}$ close to the ground as assumed by Raupach (1992), Denmead et al. (2000) and Leuning (2000). Further support comes from a test parameterisation of $T_{L}(z) u_{*} / h_{c}$ (Fig. 12c) of the form:

$$
T_{L}(z) u_{*} / h_{c}= \begin{cases}b, & a<z / h_{c} \leq 1 \\ c+\left(z / h_{c}\right)(b-c) / a, & 0 \leq z / h \leq a\end{cases}
$$

Here, $b$ is the value of $T_{L}(z) u_{*} / h_{c}$ at the top of the canopy, $c$ is the value of $T_{L}(z) u_{*} / h_{c}$ at the ground, and $T_{L}(z) u_{*} / h_{c}$ is constrained to be constant in the region $a<z / h_{c} \leq 1$ and varies linearly in the region $0 \leq z / h \leq a$. In this parameterisation (unlike the Styles et al. and MW parameterisations), $T_{L}(z) u_{*} / h_{c}$ is allowed to either increase or decrease near the ground. The optimised profile of $T_{L}(z) u_{*} / h_{c}$ was obtained by non-linear parameter estimation of $a, b$ and $c$ (with prior estimates $a=0.25, b=0.4, c=0.4$ ) and $x_{\lambda E}$, as defined above. The result, shown in Fig. 12c, produces a maximum value of $T_{L}(z) u_{*} / h_{c}$ of $0.67 \pm 0.11$ at $z=h_{c}$ decreasing to $0.10 \pm 0.10$ at the ground in the lower $46 \pm 13 \%$ of the canopy. This is in broad agreement with the optimised parameterisation of Styles et al. (2002) and the form adopted by Leuning (2000), and suggests against the elevated values of $T_{L}$ in the lower canopy predicted by the MW formulation.

Wohlfahrt (2004) arrived at a similar conclusion. He used a multilayer SVAT model in conjunction with three different formulations of $T_{L}$ (Leuning et al. 2000; Massman and Weil 1999; Raupach 1989a) and three different Lagrangian dispersion models (Baldocchi 1992; Raupach 1989b; Warland and Thurtell 2000). While the choice of Lagrangian model had little effect on predictions of $\mathrm{CO}_{2}, \mathrm{H}_{2} \mathrm{O}$ and temperature profiles within and above an alpine meadow canopy, he found that the MW parameterization resulted in poorer agreement between modelled and measured profiles than the others.

A possible explanation for the success of the Styles et al. (2002) formulation is that it consistent with a correction to the constant form (Raupach 1989a) of $T_{L}(z) u_{*} / h_{c}$ due to the production of turbulent kinetic energy $\left(W_{p}\right)$ in the wakes of canopy elements. If we assume that $T_{L}(z) u_{*} / h_{c}$ is a linear function of $W_{p}$ :

$$
\frac{T_{L}(z) u_{*}}{h_{c}}=a_{1}+a_{2} W_{p}
$$

and formulate $W_{p}$ as (Poggi et al., 2008):

$$
W_{p}=\bar{u}^{3} / L_{c},
$$

where $L_{c}$ is an adjustment length scale and $\bar{u}$ is the mean horizontal wind speed

$$
\bar{u}=u_{h_{c}} \exp \left(-\beta^{\prime}\left(z-h_{c}\right)\right)
$$

with $\beta^{\prime}=\frac{u_{h_{c}}^{2}}{2 u_{*}^{2} L_{c}}$,

then

$$
\frac{T_{L}(z) u_{*}}{h_{c}}=\frac{1}{a_{1}}\left(1+\frac{a_{2} u_{h_{c}}^{3}}{a_{1} L_{c}} \exp \left(-3 \beta^{\prime} z\right) \exp \left(3 \beta^{\prime} h_{c}\right)\right),
$$

which is equivalent to Eq. 8, with $a_{2}=-a_{1} h_{c} / u_{h_{c}}^{3}, c_{1}=3 \beta^{\prime}$ and $c_{2}=\left(1-\exp \left(-c_{1}\right)\right) / a_{1}$. 
A possible limitation to the success of the MW parameterization is that it is derived by substituting modelled profiles of $\sigma_{w}^{2}$ and the mean turbulent kinetic energy dissipation rate $(\varepsilon)$ into:

$$
T_{L}=\frac{2 \sigma_{w}^{2}}{C_{0} \varepsilon}
$$

where $C_{0}$ is the Lagrangian-Kolmogorov constant. While the model profiles of $\sigma_{w}^{2}$ and $\varepsilon$ are good estimates for many canopies (Massman and Weil 1999; Katul et al. 2004), the use of Eq. 22 may be problematic because:

(i) Equation 22 is derived by integrating the second-order Lagrangian structure function in the inertial subrange, and neglects any short-circuiting of the energy cascade or wake production;

(ii) $C_{0}$ is not a constant, but varies widely with the microscale Reynolds number.

Both of these effects are discussed in detail by Poggi et al. (2008) and references therein.

\section{Summary and Conclusions}

Mean hourly profiles of potential temperature, water vapour and $\mathrm{CO}_{2}$ from a two-week field campaign have been compared with corresponding model predictions, and used to produce a revised vertical profile of the Lagrangian time scale, $T_{L}$, within the forest canopy. Inputs to the predicted profiles were source/sink distributions from a SVAT model optimized using measured net fluxes above the canopy, and vertical profiles of the turbulence statistics, $\sigma_{w}$ and $T_{L}$. Uncertainties in the source/sink distributions were estimated from uncertainties in the gap fraction for radiation penetration, $P_{\text {gap }}$, discrepancies between observed and predicted above-canopy net fluxes, and discrepancies between two sets of independent chamber measurements of $\mathrm{CO}_{2}$ ground fluxes. While $\sigma_{w}$ was measured to very high precision, prior estimates of $T_{L}$ were uncertain. Therefore two parameterisations were adopted: that of Styles et al. (2002) and that of Massman and Weil (1999). Initial parameters for the Styles et al. (2002) formulation were obtained from a least squares fit to $T_{L}$ estimated from estimates of the Eulerian time scale, $T_{E}$ (Eqs. 6 and 5, Fig. 8). Optimisation of the $T_{L}$ parameters $\left(c_{1}\right.$ and $c_{2}$ in Eq. 8), along with a single parameter for correcting the latent heat flux at the soil $\left(x_{\lambda E}\right)$, led to agreement between observed and predicted concentrations to within the $95 \%$ confidence limits for most of the hourly mean profiles. In contrast, the optimised MW parameterization of $T_{L}$ produced poorer agreement between observations and predictions, as quantified by the associated cost functions. We conclude that the normalized profile of $T_{L}(z) u_{*} / h_{c}$ that optimizes agreement between measured and predicted concentration profiles decreases with proximity to the ground and is well described by

$$
\frac{T_{L} u_{*}}{h_{c}}=c_{2} \frac{1-\exp \left(-c_{1} z / h_{c}\right)}{1-\exp \left(-c_{1}\right)}
$$

with $c_{1}=4.86 \pm 1.52$ and $c_{2}=0.66 \pm 0.10$.

Acknowledgements We gratefully acknowledge the expert technical assistance of Steve Zegelin, Dale Hughes, Mark Kitchen, Richard Hurley, Martin Riggenbach and Graham Kettlewell. Thanks also to David Jupp for supplying the ground-based lidar data and Heather Keith and Stephen Livesley for the ground $\mathrm{CO}_{2}$ flux measurements. Mike Raupach and Ian Harman kindly reviewed the manuscript and provided helpful suggestions. 
Open Access This article is distributed under the terms of the Creative Commons Attribution Noncommercial License which permits any noncommercial use, distribution, and reproduction in any medium, provided the original author(s) and source are credited.

\section{References}

Baldocchi D (1992) A Lagrangian random-walk model for simulating water-vapor, Co-2 and sensible heat-flux densities and scalar profiles over and within a soybean canopy. Boundary-Layer Meteorol 61:113-144. doi:10.1007/BF02033998

Denmead OT (1991) Sources and sinks of greenhouse gases in the soil-plant environment. Vegetatio 91:73-86. doi:10.1007/BF00036049

Denmead OT, Harper LA, Sharpe RR (2000) Identifying sources and sinks of scalars in a corn canopy with inverse Lagrangian dispersion analysis I. Heat. Agric For Meteorol 104:67-73. doi:10.1016/ S0168-1923(00)00148-9

Denmead OT, Raupach MR, Leuning R, Dunin FX, Freney JR (2005) Inverse Lagrangian analysis of heat, vapor, and gas exchange in plant canopies. In: Sadler EJ, Ham JM, Tanner B, Baker JM, Hatfield JL (eds) Micrometeorolgical measurements in agricultural systems. American Society of Agronomy, Madison

Doherty J (1999) PEST. Watermark numerical computing, Townsville, Australia

Fest BJ, Livesley SJ, Drosler M, van Gorsel E, Arndt SK (2008) Soil-atmosphere greenhouse gas exchange in a cool, temperate Eucalyptus delegatensis forest in south-eastern Australia. Agric Forest Meteorol. doi:10.1016/j.agrformet.2008.09.007

Goudriaan J, van Laar HH (1994) Modelling potential crop growth processes, Current Issues in Production Ecology, vol 2. Kluwer, Dordrecht, p 238

Griffith DWT (2002) FTIR measurements of atmospheric trace gases and their fluxes. In: Chalmers JM, Griffiths PR (eds) Handbook of vibrational spectroscopy. Wiley, Chichester, pp 2823-2841

Harman IN, Finnigan JJ (2007) A simple unified theory for flow in the canopy and roughness sublayer. Boundary-Layer Meteorol 123:339-363. doi:10.1007/s10546-006-9145-6

Haverd V, Cuntz M, Leuning R, Keith H (2007) Air and biomass heat storage fluxes in a forest canopy: calculation within a soil vegetation atmosphere transfer model. Agric For Meteorol 147:125-139. doi:10. 1016/j.agrformet.2007.07.006

Jupp DLB, Culvenor DS, Lovell JL, Newnham GJ, Strahler AH, Woodcock CE (2008) Estimating forest LAI profiles and structural parameters using a ground based laser called "Echidna ${ }^{\circledR}$ ". Tree Physiol. doi:10. 1093/treephys/tpn022

Kaimal JC, Finnigan JJ (1993) Atmospheric boundary layer flows: their structure and measurement. Oxford University Press, New York, 289 pp

Katul G, Oren R, Ellsworth D, Hsieh CI, Phillips N, Lewin K (1997) A Lagrangian dispersion model for predicting $\mathrm{CO}_{2}$ sources, sinks, and fluxes in a uniform loblolly pine (Pinus taeda L.) stand. J Geophys Res Atmos 102:9309-9321

Katul GG, Mahrt L, Poggi D, Sanz C (2004) One- and two-equation models for canopy turbulence. Boundary-Layer Meteorol 113:81-109. doi:10.1023/B:BOUN.0000037333.48760.e5

Keith H, Wong SC (2006) Measurement of soil $\mathrm{CO}_{2}$ efflux using soda lime absorption: both quantitative and reliable. Soil Biol Biochem 38:1121-1131. doi:10.1016/j.soilbio.2005.09.012

Legg BJ, Raupach MR, Coppin PA (1986) Experiments on scalar dispersion within a model-plant canopy, vol 3. An elevated line source. Boundary-Layer Meteorol 35:277-302. doi:10.1007/BF00123645

Leuning R (1995) A critical-appraisal of a combined stomatal-photosynthesis model for C-3 plants. Plant Cell Environ 18:339-355. doi:10.1111/j.1365-3040.1995.tb00370.x

Leuning R (2000) Estimation of scalar source/sink distributions in plant canopies using Lagrangian dispersion analysis: corrections for atmospheric stability and comparison with a multilayer canopy model. Boundary-Layer Meteorol 96:293-314. doi:10.1023/A:1002449700617

Leuning R, Kelliher FM, Depury DGG, Schulze ED (1995) Leaf nitrogen, photosynthesis, conductance and transpiration—scaling from leaves to canopies. Plant Cell Environ 18:1183-1200. doi:10.1111/j. 1365-3040.1995.tb00628.x

Leuning R, Denmead OT, Miyata A, Kim J (2000) Source/sink distributions of heat, water vapour, carbon dioxide and methane in a rice canopy estimated using Lagrangian dispersion analysis. Agric For Meteorol 104:233-249. doi:10.1016/S0168-1923(00)00158-1

Massman WJ, Weil JC (1999) An analytical one-dimensional second-order closure model of turbulence statistics and the Lagrangian time scale within and above plant canopies of arbitrary structure. Boundary-Layer Meteorol 91:81-107. doi:10.1023/A:1001810204560 
Nemitz E, Sutton MA, Gut A, San Jose R, Husted S, Schjoerring JK (2000) Sources and sinks of ammonia within an oilseed rape canopy. Agric For Meteorol 105:385-404. doi:10.1016/S0168-1923(00)00205-7

Ogee J, Brunet Y (2002) A forest floor model for heat and moisture including a litter layer. J Hydrol (Amst) 255:212-233. doi:10.1016/S0022-1694(01)00515-7

Poggi D, Katul G, Cassiani M (2008) On the anmalous behavior of the Lagrangian structure function similarity constant inside dense canopies. Atmos Environ 42:4212-4231. doi:10.1016/j.atmosenv.2008.01.020

Raupach MR (1989a) Applying Lagrangian fluid-mechanics to infer scalar source distributions from concentration profiles in plant canopies. Agric For Meteorol 47:85-108. doi:10.1016/0168-1923(89)90089-0

Raupach MR (1989b) A practical Lagrangian method for relating scalar concentrations to source distributions in vegetation canopies. Q J R Meteorol Soc 115:609-632. doi:10.1002/qj.49711548710

Raupach MR (2001) Inferring biogeochemical sources and sinks from atmospheric concentrations: general considerations and applications in vegetation canopies. In: Schulze ED (ed) Global biogeochemical cycles in the climate system. Academic Press, San Diego, p 350

Raupach MR, Denmead OT, Dunin FX (1992) Challenges in Linking atmospheric $\mathrm{CO}_{2}$ concentrations to fluxes at local and regional scales. Aust J Bot 40:697-716. doi:10.1071/BT9920697

Raupach MR, Finnigan JJ, Brunet Y (1996) Coherent eddies and turbulence in vegetation canopies: the mixing-layer analogy. Boundary-Layer Meteorol 78:351-382. doi:10.1007/BF00120941

Ross PJ (2003) Modeling soil water and solute transport-fast, simplified numerical solutions. Agron J 95: 1352-1361

Sellers PJ (1985) Canopy reflectance, photosynthesis and transpiration. Int J Remote Sens 6:1335-1372. doi:10.1080/01431168508948283

Siqueira M, Katul G, Lai CT (2002) Quantifying net ecosystem exchange by multilevel ecophysiological and turbulent transport models. Adv Water Resour 25:1357-1366. doi:10.1016/S0309-1708(02)00061-1

Siqueira M, Leuning R, Kolle O, Kelliher FM, Katul GG (2003) Modelling sources and sinks of $\mathrm{CO}_{2}, \mathrm{H}_{2} \mathrm{O}$ and heat within a Siberian pine forest using three inverse methods. Q J R Meteorol Soc 129:1373-1393. doi:10.1256/qj.02.108

Styles JM, Raupach MR, Farquhar GD, Kolle O, Lawton KA, Brand WA, Werner RA, Jordan A, Schulze ED, Shibistova O, Lloyd J (2002) Soil and canopy $\mathrm{CO}_{2},\left(\mathrm{CO}_{2}\right)-\mathrm{C}-13, \mathrm{H}_{2} \mathrm{O}$ and sensible heat flux partitions in a forest canopy inferred from concentration measurements. Tellus B Chem Phys Meterol 54:655-676. doi:10.1034/j.1600-0889.2002.01356.x

Tiwary A, Fuentes JD, Barr JG, Wang D, Colls JJ (2007) Inferring the source strength of isoprene from ambient concentrations. Environ Modell Softw 22:1281-1293. doi:10.1016/j.envsoft.2006.09.002

Wang YP, Leuning R (1998) A two-leaf model for canopy conductance, photosynthesis and partitioning of available energy I: model description and comparison with a multi-layered model. Agric For Meteorol 91:89-111. doi:10.1016/S0168-1923(98)00061-6

Warland JS, Thurtell GW (2000) A Lagrangian solution to the relationship between a distributed source and concentration profile. Boundary-Layer Meteorol 96:453-471. doi:10.1023/A:1002656907873

Wohlfahrt $\mathrm{G}$ (2004) Modelling fluxes and concentrations of $\mathrm{CO}_{2}, \mathrm{H}_{2} \mathrm{O}$ and sensible heat within and above a mountain meadow canopy: a comparison of three Lagrangian models and three parameterisation options for the Lagrangian time scale. Boundary-Layer Meteorol 113:43-80. doi:10.1023/B:BOUN. $0000037326.40490 .1 \mathrm{f}$ 